Research Article

\title{
Impact Assessment of Flammable Gas Dispersion and Fire Hazards from LNG Tank Leak
}

\author{
Lifeng Li $\mathbb{D}^{1,2}$ Jinheng Luo, ${ }^{1}$ Gang Wu, ${ }^{1}$ Xinhong Li, ${ }^{3}$ Nan Ji, ${ }^{1}$ and Lixia Zhu ${ }^{1}$ \\ ${ }^{1}$ State Key Laboratory of Performance and Structural Safety for Petroleum Tubular Goods and Equipment Materials, \\ CNPC Tubular Goods Research Institute, Xi'an 710077, China \\ ${ }^{2}$ Collage of Pipeline and Civil Engineering, China University of Petroleum, Shandong, Qingdao 266580, China \\ ${ }^{3}$ School of Resources Engineering, Xi'an University of Architecture and Technology, Xi'an 710055, Shaanxi, China \\ Correspondence should be addressed to Lifeng Li; 457761448@qq.com
}

Received 20 May 2021; Revised 16 July 2021; Accepted 19 August 2021; Published 12 October 2021

Academic Editor: Babak Shotorban

Copyright (c) 2021 Lifeng Li et al. This is an open access article distributed under the Creative Commons Attribution License, which permits unrestricted use, distribution, and reproduction in any medium, provided the original work is properly cited.

\begin{abstract}
This study conducts an impact assessment of flammable gas dispersion and fire hazards from LNG tank leak. The release source model is used to estimate LNG release rate. A CFD (computational fluid dynamics) based 3D model is established to simulate dispersion behavior of flammable gas from the phase transformation of LNG. Subsequently, a FDS (fire dynamics) based model is built to simulate the pool fire due to LNG tank leak. The impact of gas dispersion and fire on personnel and assets is assessed based on simulation results, which can provide a theoretical basis and method support for major accident assessment of tank leakage in large LNG receiving station. The results show that the dispersion of flammable gas from LNG tank leak has an obvious stage characteristic. The flammable gas reached a steady state around $300 \mathrm{~s}$, and the corresponding coverage area is about $16250 \mathrm{~m}^{2}$. The pool fire simulations indicate that the steady flame is formed at $20 \mathrm{~s}$. The flames flow along the wind, and the maximum temperature of the fire reaches $670^{\circ} \mathrm{C}$, and the maximum thermal radiation reaches $624 \mathrm{~kW} / \mathrm{m}^{2}$. According to the fire damage criteria, the pool fire from LNG tank leak may pose a serious threat on the safety of adjacent assets and personnel.
\end{abstract}

\section{Introduction}

Liquefied natural gas (LNG) is characteristic by easy to leak and volatile diffusion, flammability, and explosion. Once the LNG leak accident occurs, it will have a catastrophic impact on human life, assets, and the environment. The dispersion law of combustible gas and the consequences of fire and explosion accidents have become the critical of current research to ensure safety operation of LNG storage tank.

Researches on dispersion of flammable gas include field experiments, wind tunnel tests, and numerical simulation, which was carried out earlier in foreign countries. Koopman et al. [1] obtained numerous data on the dispersion distance based on Burro series of large-scale LNG leakage and dispersion experiments. Hirst and Eyre [2] studied the combustion of large gas clouds evolved from LNG and refrigerated liquid propane spills on the sea through Maplin Sands series of experiments. Brown et al. [3] detected the variation of LNG gas concentration and temperature from multiple leakage point through Falcon series of experiments. Based on wind tunnel tests, the impact on LNG release dispersion, e.g., wind speed, vortex induction, overflow rate, and leakage amount, and dangerous range can be obtained $[4,5]$.

Numerical simulation has the advantages of low cost, short cycle, simple operation, wide application range, and easy access to comprehensive data. A lot of research studies were conducted on LNG leakage and diffusion based on CFD model. Calay and Hodlo [6] used Euler-Lagrange calculation model to simulate the evaporation and dispersion of LNG gas after injection from a circular hole. Guo et al. [7] used CFD model to study the LNG vapor dispersion law under different atmospheric stability. Luo et al. [8] proposed an integrated multiphase CFD model to simulate the LNG leakage, evaporation, and diffusion process. Saleem et al. [9] proposed a comprehensive dynamic CFD model for 
large-scale land-based LNG storage tanks. Zhu [10] discussed the mathematical model of the release and dispersion process in LNG leakage accidents. Qi et al. [11] simulated the vapor dispersion of LNG in the atmosphere. Zhuang [12] simulated the wind field and leakage diffusion of LNG fullcapacity storage tanks. Zhang [13] studied the influence of factors, such as wind field, leak location, and leakage volume, and other factors on the LNG leakage and diffusion process in the storage tank area. Jiang [14] assessed the impact of cofferdam on LNG leakage. Zhang et al. [15] analyzed the possible hazards during transportation to LNG carriers after the accident. Zhou et al. [16] studied the characteristics of the three processes of large-scale LNG storage tank leakage, liquid pool evaporation, and gas cloud diffusion at receiving stations. Yang et al. [17] established a three-dimensional numerical model for a large LNG storage tank in an LNG receiving station in southern China.

In addition, a lot of studies were devoted to the risk assessment of accident consequences. Li et al. [18] simulated the thermal response process of vertical full-capacity storage tank under different fire conditions. Sun et al. [19] and Xie et al. [20] studied the features of large LNG pool fire. Di and Chen [21] studied the development law of the flame in the set LNG fire scene. Furthermore, the hazardous area caused by LNG leakage accident, e.g., fire, explosion, and the like, can be simulated [22-24]. Based on hazardous features and main dangerous accidents, the consequence simulation and quantitative assessment on various accident can be obtained [25] and used to assess the risk of LNG storage system [26]. Some researches focus on the effect on fire or explosion accidents. Baalisampang et al. [27] proposed a methodology to model an integrated impact of evolving accident scenarios. Pio et al. [28] evaluated the effect of released fuel and its composition on the thermochemical characteristics of the small-scale LNG pool fire. Lv et al. [29] developed a correlation of the maximum explosion overpressure in the LNG storage tank area based on the momentum conservation equation and the deduced factors in the explosion test. Jujuly et al. [30] studied the effect of environmental conditions on the domino of an LNG pool fire. Wei [31] studied the impact of wind seeped and leakage location on accidents caused by fire and explosion.

Although a lot of progress on assessments of LNG storage tank accidents have been made, most previous studies mainly focused on LNG leakage or fire and explosion accidents. It indicates a relatively independence between them in which there is little correlation. Thus, the cascading disaster-causing process mechanism of LNG storage tank from leakage to fire and explosion cannot be described. Process characteristics of LNG storage tank leakage fire and explosion accident still need further study. In addition, the influence of the evaporation phase variation on the dispersion process is not taken into consideration using the simplified leakage source conditions, which fails to accurately characterize the LNG dispersion process by obtained leakage rate. Therefore, the law of the phase change process caused by the temperature needs to be further studied.

This article proposes an impact assessment of flammable gas dispersion and fire hazards from LNG tank leak. Based on previous research results, the phase transformation and the mechanism of cascade disaster of large-scale LNG storage tank leakage is fully taken into consideration and systematically studied to assess accident impacts. Firstly, the mechanism of LNG phase change and dispersion cascading pool fire was revealed by identifying the location distribution characteristics of large LNG storage tanks and the phase change process of leakage sources. Secondly, the risk factors of disaster chain are analyzed to obtain the impact of LNG leakage disasters on personnel, equipment, and environmental safety. Finally, a large-scale LNG leakage chain disaster assessment method based on the phase transformation dispersion cascade process of pool fire disasters is formed, which provides the theoretical basis and method support for assessing significant leakage accidents of storage tanks in large-scale LNG receiving stations.

\section{Methodology}

Figure 1 presents the flowchart of impact assessment of flammable gas release, dispersion, and fire hazards from LNG tank leak. The main steps of the methodology include (1) establishing release source model; (2) mathematical model of gas evaporation and dispersion; and (3) mathematical model of fire.

2.1. Release Source Model. This article mainly studies the continuous leakage of the liquid phase space in the lower part of the LNG storage tank and the dispersion behavior of the LNG after the formation of a stable liquid pool on the ground. LNG storage tanks of liquid leakage rate can be calculated by the following equation:

$$
Q_{L}=C_{d} A \rho_{1} \sqrt{2 g h+\frac{2\left(P_{t}-P_{0}\right)}{\rho}},
$$

where $Q_{L}$ is the leakage mass flow, $\mathrm{kg} / \mathrm{s} ; A$ is the hole area, $\mathrm{m}^{2} ; C_{d}$ is the liquid leakage coefficient; $\rho_{1}$ is the liquid density in the storage tank, $\mathrm{kg} / \mathrm{m}^{3} ; h$ is the height of the leakage location from the fluid level in the tank, $m ; P_{t}$ is the pressure in the storage tank, $\mathrm{Pa}$; and $P_{0}$ is the pressure of the external environment, $\mathrm{Pa}$.

When the liquid in the storage tank leaks to the ground, it will spread around with the leak source as the circle's center. If there are no obstacles in the dispersion process, the radius of the liquid pool will continue to increase and reach the maximum at a certain moment. The relationship between the radius $r$ of the liquid pool and the time $t$ can be calculated by the following equation:

$$
r_{(t)}=\left(\frac{t}{\sqrt[3]{9 \pi \rho_{2} / 32 g Q}}\right)^{3 / 4},
$$

where $Q$ is the mass flow rate of the liquid that leaks to the ground to form the liquid pool, $\mathrm{kg} / \mathrm{s}$, and $\rho$ is the density of the liquid $\mathrm{LNG}, \mathrm{kg} / \mathrm{m}^{3}$.

The LNG in the liquid pool will continue to diffuse in the atmosphere through evaporation to produce LNG vapor. Due to the low temperature of the leaked LNG, it forms a 


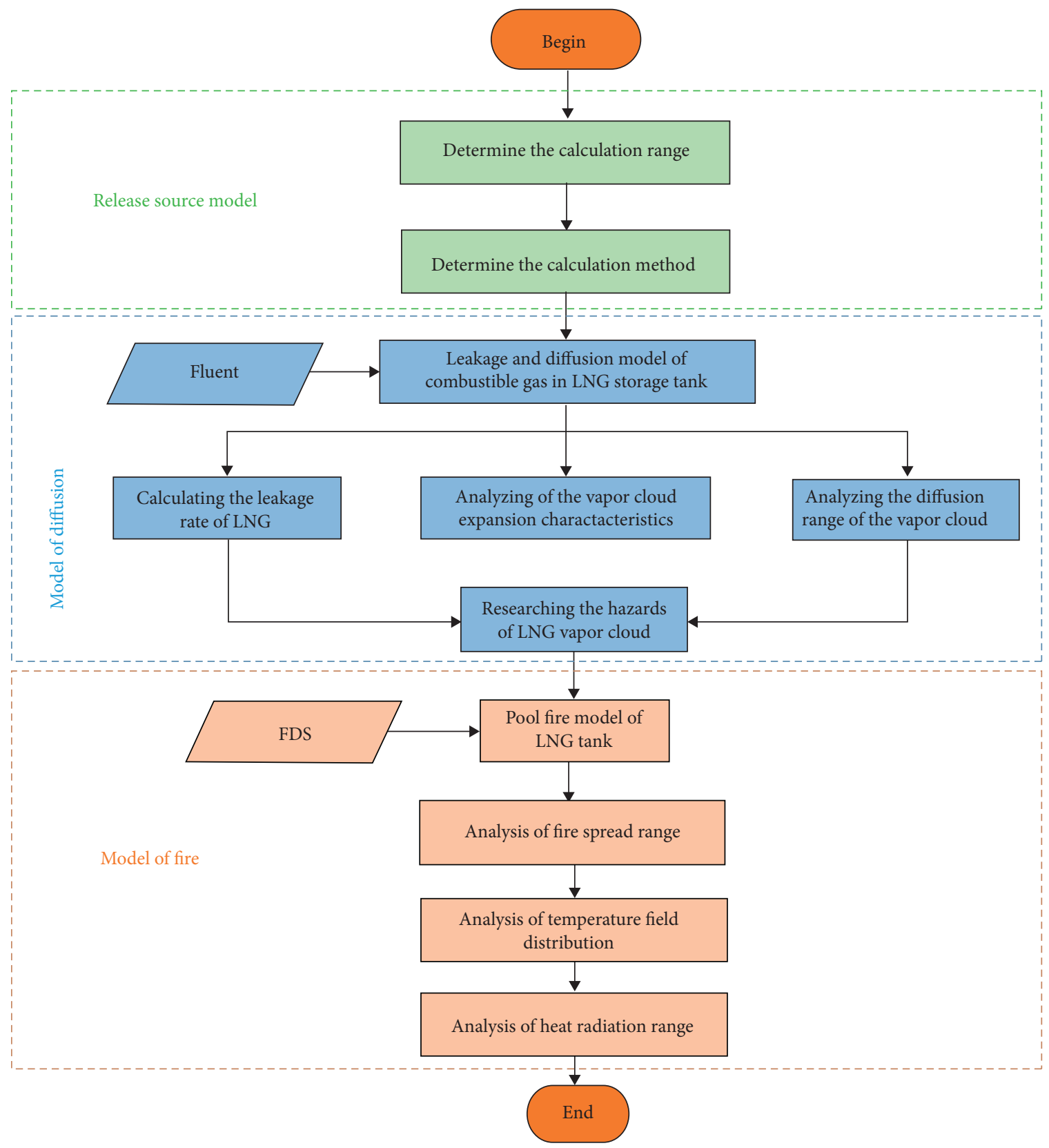

FIgURE 1: Flowchart of the proposed methodology.

significant temperature difference with the external environment. When LNG leaks to the ground, the temperature difference with the ground will cause the liquid pool to evaporate. The main form of evaporation is heat conduction evaporation. The evaporation rate caused by heat conduction is calculated by the following equation:

$$
Q_{1}=\frac{k B\left(T-T_{0}\right)}{H \sqrt{\pi \alpha t}},
$$

where $k$ is the thermal conductivity of the substance, $\mathrm{J} /$ $(\mathrm{m} \cdot \mathrm{s} \cdot \mathrm{K}) ; B$ is the area of the liquid pool, $\mathrm{m}^{2} ; \mathrm{T}$ is the ambient temperature, $\mathrm{K} ; T_{0}$ is the boiling point of the liquid under normal pressure, $\mathrm{K} ; H$ is the latent heat of vaporization of the liquid, $\mathrm{J} / \mathrm{kg}$; and $\alpha$ is the thermal dispersion coefficient, $\mathrm{m}^{2} / \mathrm{s} ; t$ is the evaporation time, $s$.

2.2. Mathematical Model of Gas Evaporation and Dispersion. Based on fluid mechanics theory, the flammable gas dispersion model of LNG storage tanks is built by Fluent as a tool for LNG leak diffusion process simulation. The study of LNG leakage dispersion behavior is mainly based on two aspects: the calculation of LNG leakage rate and the analysis of Characteristics of vapor cloud expansion of LNG leak. According to the leakage rate, the scope of LNG leakage and the scope of vapor cloud formation after LNG leakage, the hazard of vapor cloud after LNG leakage is studied. 
Fluent is used to simulate the flow process of fluids. The flow of fluids is governed by the laws of conservation of physics, and the fluid flow process is calculated through control equations. Because the LNG in this study gasifies and then forms a mixture with air after the leak, the Mixture theoretical model is selected. The governing equations include mass conservation equation, momentum conservation equation, and energy conservation equation. These three conservation equations can be expressed in a unified mathematical expression that is the governing equation (4).

$$
\frac{\partial}{\partial t}(\rho \varphi)+\operatorname{div}(\rho \bar{u} \varphi)=\operatorname{div}(\Gamma \operatorname{grad} \varphi)+S,
$$

where $\rho$ is the density, $\varphi$ is the general variable, $\Gamma$ is the dispersion coefficient, and $S$ is the source term.

The Realizable k-model introduces variables related to rotation and curvature in the turbulence intensity coefficient equation. This model can consider the anisotropy in the turbulent flow process and can be effectively used for curved wall flow and curved streamline flow. The expression of the Realizable k-turbulence model is as follows.

$K$ equation:

$$
\frac{\partial(\rho k)}{\partial t}+\frac{\partial\left(\rho k u_{i}\right)}{\partial x_{i}}=\frac{\partial}{\partial x_{i}}\left[\left(\mu+\frac{\mu_{t}}{\sigma_{k}}\right) \cdot \frac{\partial k}{\partial x_{i}}\right]+G_{k}+G_{b}-\rho \varepsilon-\gamma_{M} \text {. }
$$

$\varepsilon$ equation:

$$
\begin{aligned}
\frac{\partial(\rho k)}{\partial t}+\frac{\partial\left(\rho k u_{i}\right)}{\partial x_{j}}= & \frac{\partial}{\partial x_{j}}\left[\left(\mu+\frac{\mu_{t}}{\sigma_{\varepsilon}}\right) \cdot \frac{\partial k}{\partial x_{j}}\right] \\
& +\rho C_{1} S_{c}-\rho C_{2} \frac{\varepsilon^{2}}{k+\sqrt{v \varepsilon}}+C_{1 \varepsilon} \frac{\varepsilon}{k} C_{3 \varepsilon} G_{b}
\end{aligned}
$$

where $C_{1 \varepsilon}, C_{3 \varepsilon}, C_{1}, C_{2}, \sigma_{k}$, and $\sigma_{\varepsilon}$ are constants. $C_{1}=\max [0.43,(\eta / \eta+5)]$.

$G_{k}$ represents the turbulent energy term due to the existence of the velocity gradient:

$$
G_{k}=-\rho \overline{u_{i}^{\prime} u_{j}^{\prime}} \frac{\partial u_{j}}{\partial u_{i}}
$$

$G_{b}$ represents the turbulent energy item due to buoyancy:

$$
G_{b}=\beta g_{i} \frac{\mu_{i}}{p \tau_{i}} \frac{\partial T}{\partial x_{i}}
$$

where $g_{i}$ represents the component of gravity in the direction; $\beta$ represents the coefficient of thermal expansion, $\beta=-(1 / \rho)(\partial \rho / \partial T) ; \quad G(\mathrm{Gas})=-g_{i}\left(\mu_{\gamma} / p_{\gamma_{i}}\right)(\partial \rho /$ $\left.\partial x_{i}\right)$, in which $p_{\gamma_{i}}$ is the Prandtl number; from the $\mathrm{K}$ equation, and it can be found that the turbulent kinetic energy growth trend mainly appears in the unstable layer. For stable layers, buoyancy tends to suppress turbulent flow.

The dispersion behavior of LNG leakage belongs to the flow of multicomponent substances. The mass content of each substance can be predicted by iteratively solving the conservation equation of transport and dispersion of each substance. The material transport and dispersion equation are shown in the following equation:

$$
\frac{\partial}{\partial_{t}}(\rho h)=\nabla \cdot\left(\rho \bar{v} \gamma_{i}\right)=-\nabla \cdot \overline{J_{i}},
$$

where $\gamma_{i}$ is the mass content of substance $i$ and $\overline{J_{\mathrm{i}}}$ is the mass dispersion rate of the substance.

In the turbulent flow process, the mass dispersion equation is expressed as

$$
\overline{J_{i}}=-\left(\rho D_{i, m}+\frac{\mu_{i}}{S_{c t}}\right) \nabla \gamma_{i}
$$

LNG is a liquid state, which is transferred with the heat of the air and gasified into natural gas. The LNG evaporation phase change model was written in FLUENT. The model proposed by Lee $\mathrm{W} \mathrm{H}$ is the most widely used. The mass transfer equation of the two phases is as follows:

$$
\begin{aligned}
& T_{\text {mix }}>T_{\text {sat }}, m_{l \longrightarrow v}=b \alpha_{l} \rho_{l} \frac{\left(T-T_{\text {sat }}\right)}{T_{\text {sat }}}, \\
& T_{\text {mix }}<T_{\text {sat }}, m_{v \longrightarrow l}=b \alpha_{v} \rho_{v} \frac{\left(T_{\text {sat }}-T\right)}{T_{\text {sat }}},
\end{aligned}
$$

where $T_{\text {mix }}$ is the unit temperature of the mixing zone, $K$; $T_{\text {sat }}$ is the saturation temperature, $K ; m_{l \longrightarrow v}$ is the phase change rate of the liquid phase into the gas phase, $\mathrm{kg} /\left(\mathrm{m}^{3} \cdot \mathrm{s}\right)$; $m_{v \longrightarrow l}$ is the phase change rate of the gas phase into the liquid phase, $\mathrm{kg} /\left(\mathrm{m}^{3} \cdot \mathrm{s}\right)$; and $b$ is a factor that controls the intensity of the phase transition. According to the simulation of the hydrocarbon feedstock flow and evaporation process by Schepper et al., $b$ is taken as $0.1 \mathrm{~s}^{-1} ; \alpha_{l}$ and $\alpha_{v}$ are the surface tensions of the liquid and gas phases, respectively, $\mathrm{N} / \mathrm{m}$; and $\rho_{l}$ and $\rho_{v}$ are the densities of liquid phase and gas phase, respectively, $\mathrm{kg} / \mathrm{m}^{3}$.

2.3. Mathematical Model of Fire. FDS is a fire of driven fluid flow dynamics software. It uses FDS to model sea surface gas fire accidents, simulates fire and smoke formation by solving low Mach number NS equations, and predicts heat flow and the concentration of toxic substances produced by the fire. The large eddy simulation (LES) method considers the turbulence characteristics in the heat flow process. During the fire development process, the smoke and heat flow obey the conservation of mass, momentum, energy, and component transport equations:

$$
\begin{aligned}
& \frac{\partial \rho_{g}}{\partial t}+\nabla \cdot \rho_{g} u=0, \\
& \frac{\partial}{\partial t}\left(\rho_{g} u\right)+\nabla \cdot \rho_{g} u u+\nabla p=\rho_{g} f+\nabla \cdot \tau_{i j}, \\
& \frac{\partial}{\partial t}\left(\rho_{g} h_{e}\right)+\nabla \cdot \rho_{g} h_{e} u=\frac{D p}{D t}+\overrightarrow{q^{\prime \prime \prime}}-\nabla \cdot q+\phi, \\
& \frac{\partial}{\partial t}\left(\rho_{g} Y_{i}\right)+\nabla \cdot \rho_{g} Y_{i} u=\nabla \cdot \rho_{g} D_{i} \nabla Y_{i}+\overrightarrow{m_{i}^{\prime \prime \prime}},
\end{aligned}
$$


where $\rho_{g}$ is gas density, $\mathrm{kg} / \mathrm{m}^{3} ; t$ is time, $s ; u$ is the velocity vector, $\mathrm{m} / \mathrm{s} ; \nabla$ is the Laplace operator; $p$ is pressure, $\mathrm{Pa} ; f$ is the external force vector, $\mathrm{N} ; \tau_{i j}$ is the viscosity vector, $\mathrm{Pa} \cdot \mathrm{s} ; h_{e}$ is the enthalpy value of leakage gas components, $\mathrm{kJ} / \mathrm{kg} ; \underset{q^{\prime \prime}}{\longrightarrow}$ is the heat release rate per unit volume of gas, $\mathrm{kw} / \mathrm{m}^{3} ; q$ is radiant heat flux, $\mathrm{kw} / \mathrm{m}^{2} ; \varphi$ is the dissipation rate, $\mathrm{kw} / \mathrm{m}^{3} ; Y_{i}$ is the mass fraction of the $i$-th component of the leakage gas; $D_{i}$ is the dispersion coefficient of the $i$-th component, $\mathrm{m}^{2} / \mathrm{s}$; and $\underset{m_{i}^{\prime \prime \prime}}{\longrightarrow}$ is the unit volume generation rate of the $i$-th component, $\mathrm{kg} / \mathrm{m}^{3} \cdot \mathrm{s}$.

Thermal radiation is a vital damage index of fire. The control equation of FDS thermal radiation calculation is as follows:

$$
\begin{aligned}
\overrightarrow{q_{r}^{\prime \prime \prime}} & \equiv-\nabla \cdot \overrightarrow{q_{r}^{\prime \prime}}(x)=k(x)\left[U(x)-4 \pi I_{b}(x)\right], \\
U(x) & =\int_{4 \pi} I\left(x, s^{\prime}\right) \mathrm{d} s^{\prime},
\end{aligned}
$$

where $k(x)$ is the absorption coefficient; $I_{b}(x)$ is the source term; and $I(x, s)$ is the solution of the nonscattering grey gas radiation transport equation.

\section{Model Establishment}

3.1. LNG Tank Farm. At present, my country's LNG receiving stations generally adopt the LNG full-capacity storage tank type and most of the completed receiving stations have a capacity of $160,000 \mathrm{~m}^{3}$. The storage tank type is a full-capacity storage tank; the storage capacity is $16 \times 104 \mathrm{~m}^{3}$; the storage temperature is $-162^{\circ} \mathrm{C}$; and the maximum liquid level is $34.6 \mathrm{~m}$. The minimum liquid level is $2.9 \mathrm{~m}$; and the normal working pressure range is $0.3 \sim 0.7 \mathrm{MPa}$. Take a specific LNG receiving station as the research object for analysis. The overall overview of LNG receiving station is shown in Figure 2.

\subsection{Dispersion Model of Combustible Gas Leakage from LNG Tank}

3.2.1. Determination of the Calculation Domain of Leakage Dispersion. The LNG storage tank is in a completely open environment, but due to the necessity and time problems, it is not necessary to simulate the wind field of the entire atmosphere and the gas dispersion in the simulation process. In this study, the size of the calculation area was set as $640 \mathrm{~m} \times 300 \mathrm{~m} \times 100 \mathrm{~m}$. The LNG tank area model is established in the calculation domain, including six storage tanks. The upper storage tanks are numbered \#1, \#2, and \#3 from left to right. The lower storage tanks are numbered \#4, $\# 5$, and \#6 from left to right.

The numerical model adopts the finite volume method, and the process of meshing is to discretize the computational domain. The quantity and quality of meshing determine the computational time and precision, and the meshing should meet the requirements of computational accuracy, computational time, computer configuration, and other aspects. The vicinity of the leak location is a vital calculation domain

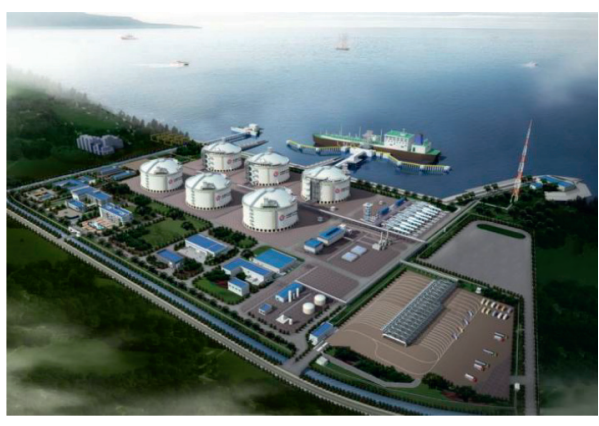

FIGURE 2: Overall overview of LNG receiving station.

for phase change and gas dispersion, and the calculation importance of the calculation domain far away from the leakage dispersion location gradually decreases, so this article uses a gradual unstructured grid to mesh the entire calculation domain. The size of the grid at the site of the leak (initial grid size) is $0.05 \mathrm{~m}$, the expansion coefficient of the grid is 1.2 , and the maximum grid size is $4.5 \mathrm{~m}$. The meshing of the entire computational domain is shown in Figure 3. The grid division near the leak is shown in Figure 4, and the total number of grids reaches 4027679 .

\subsubsection{Boundary Conditions}

(1) Setting of Wind Speed. LNG vapor cloud dispersion is mainly driven by wind. Wind direction determines the dispersion direction of methane vapor, and wind speed affects the dispersion speed of methane vapor. Because the wind is affected by the surface conditions and atmospheric temperature, the change of wind speed gradient caused by atmospheric height should be considered in the actual engineering calculation. Wind speed profile exponential equation is usually used to describe wind speed gradient changes in the environment, as shown in the following equation:

$$
u_{z}=u_{10}\left(\frac{Z}{10}\right)^{0.091} .
$$

(2) Boundary Conditions and Parameter Setting for Wind Field Calculation.

(1) Boundary condition setting: Fluent's solution process is that the data are extended from the boundary or boundary surface to the whole calculation region. Reasonable boundary conditions are the key to ensure the accuracy and correctness of the model. The setting of boundary conditions should conform to the actual situation of simulation.

When the wind field in the whole calculation domain is simulated, the boundary conditions are set as shown in Table 1.

(2) Pressure-velocity coupling: after the wind field is stable, the transient calculation method is used to solve the velocity distribution in the calculation domain, and SIMPLE can provide a more conservative computational convergence. Therefore, the 


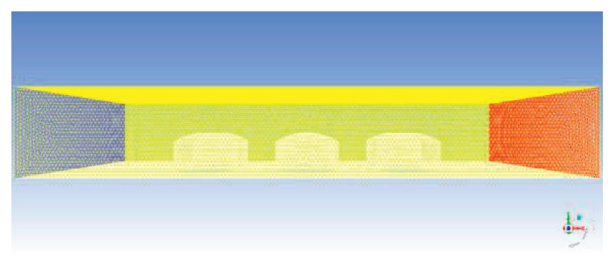

FIGURE 3: Overall grid model of the LNG receiving station.

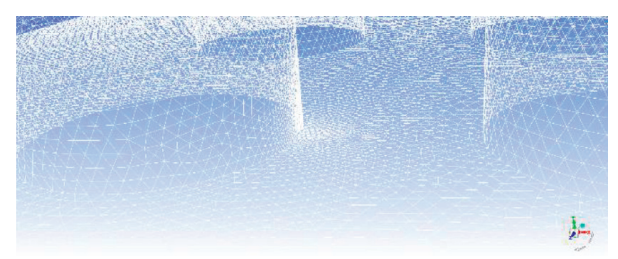

Figure 4: Mesh division near the leakage port.

TABLE 1: LNG storage tank leakage and dispersion calculation area boundary types.

\begin{tabular}{|c|c|c|c|}
\hline Boundary name & Boundary type & Boundary name & Boundary type \\
\hline The left side of computing domain (wind inlet) & VELOCITY_INLET & Tank wall & \\
\hline Leal & & The comput & TRY \\
\hline Grou & & & \\
\hline The right side of the computational domain (outlet) & OUT_FLOW & The backside of the computational field & SYMMETRY \\
\hline
\end{tabular}

SIMPLE algorithm is used as the pressure and velocity coupling method of the wind field.

(3) Boundary Conditions and Solution Parameters of LNG Evaporation and Dispersion.

(1) Boundary condition setting: the LNG storage tank leakage dispersion boundary condition setting only needs to change the leakage port in the boundary type of the wind field calculation area, as shown in Table 1 . The mass flow is $436.6 \mathrm{~kg} / \mathrm{m}^{3}$, and the other boundary types remain the same.

(2) LNG material definition: LNG is a liquid mixture, and the meaning does not exist in the material library. Therefore, the user needs to define it by himself. When determining the material, the relevant physical and chemical property data of the substance is required. The basic parameters of LNG materials are shown in Table 2.

Define the properties of the LNG material and write the function file by writing the Fluent database file. Place it in the Fluent working directory, the system will automatically load this database, and new materials can be provided.

(3) The setting of solution model: the LNG release and dispersion process involve three-phase air, LNG and methane, and this article chooses a Mixture model to solve the entire leakage dispersion process. The transient calculation is used to simulate the leakage dispersion, to observe the situation of LNG leakage dispersion at any moment. PISO algorithm is used for pressure and velocity coupling, which is suitable for transient calculation, ensuring the convergence of the model and speeding up the calculation speed.

\subsection{Pool Fire Model of LNG Tank}

3.3.1. Determination of the Calculation Domain of Pool Fire. According to the tank farm layout in 3.2.1, a fire simulation model of the LNG receiving station tank farm is established in Pyrosim. The model is shown in Figure 5. The leakage port is located on the wall of \# 4 tank, which is $6 \mathrm{~m}$ above the ground, and is closest to \# 5 tank. Liquid LNG flows out from the leak port to the bottom and generates a liquid pool. Because the temperature of the liquid LNG is very low and the outside temperature forms a large temperature difference, the liquid pool itself will continue to evaporate due to heat conduction. The radius of the ground liquid pool reaches a stable maximum when the release mass rate is equal to the evaporation rate of the liquid pool. The model in this study selects the largest liquid pool when it reaches a steady state, and this liquid pool is used in the ignition source for fire analysis.

\subsubsection{The LNG Tank Fire Simulation Parameters}

(1) Fire Atmospheric Conditions Setting. The atmospheric conditions are set by the simulation settings of gas release and dispersion, and the environmental conditions of LNG tank are set according to the actual conditions as shown in Table 4. 
TABLE 2: LNG physical and chemical parameters.

\begin{tabular}{lccc}
\hline Physical and chemical parameters & Numerical value & Physical and chemical parameters & Numerical value \\
\hline Density $\left(\mathrm{kg} / \mathrm{m}^{3}\right)$ & 430 & Thermal conductivity $(\mathrm{W} /(\mathrm{m} \cdot \mathrm{K}))$ & 0.21 \\
Kinematic viscosity $(\mathrm{kg} /(\mathrm{m} \cdot \mathrm{s}))$ & 0.0001183 & Saturated vapor pressure $(\mathrm{Pa})$ & Piecewise function representation \\
Latent heat of vaporization $(\mathrm{J} / \mathrm{kg})$ & 509332 & Heat release during pyrolysis $(\mathrm{J} / \mathrm{kg})$ & 0 \\
Vaporization temperature $(\mathrm{K})$ & 90.7 & The surface tension of the droplet $(\mathrm{N} / \mathrm{m})$ & 0.0133 \\
Specific heat capacity $(\mathrm{J} / \mathrm{kg} \cdot \mathrm{K})$ & 2055 & Boiling point $(\mathrm{K})$ & 111.66 \\
\hline
\end{tabular}

Note. The saturated vapor pressure in the table is a value that changes with temperature, which is defined by a piecewise linear function, as shown in Table 3 .

TABLE 3: LNG saturated vapor pressure piecewise linear function setting.

\begin{tabular}{lcccccc}
\hline Split point & 1 & 2 & 3 & 4 & 5 & \multicolumn{1}{c}{5} \\
\hline Temperature $(\mathrm{K})$ & 90.7 & 92 & 94 & 96 & 98 & 100 \\
Saturated vapor $(\mathrm{Pa})$ & 11719 & 13853 & 17679 & 22314 & 27877 & 34495 \\
Split point & 7 & 8 & 9 & 106 & 10 & 11 \\
Temperature $(\mathrm{K})$ & 102 & 104 & 62063 & 74324 & 110 & 88389 \\
Saturated vapor $(\mathrm{Pa})$ & 42302 & 51441 & 11.6 & 101325 \\
\hline
\end{tabular}

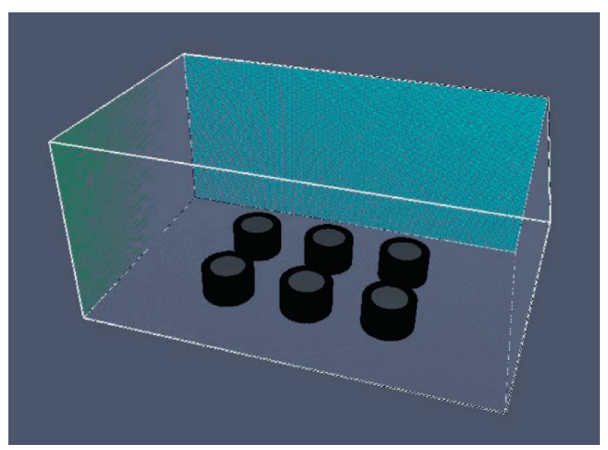

Figure 5: Tank farm model of the LNG receiving station.

TABLE 4: Setting of atmospheric environment parameters of the LNG tank farm.

\begin{tabular}{lcccc}
\hline Wind speed $(\mathrm{m} / \mathrm{s})$ & Wind direction & Temperature gradient $\left({ }^{\circ} \mathrm{C} / \mathrm{m}\right)$ & Atmospheric stability & Ambient temperature $(\mathrm{K})$ \\
\hline 5 & $\mathrm{~S}$ & 0.015 & Better & 300 \\
\hline
\end{tabular}

(2) Reaction Setting. LNG mainly contains methane, and it is used as a reactant to participate in the fire reaction.

(3) Mesh Division and Distribution of Measuring Points. The boundary size of the computational domain is determined to be $640 \mathrm{~m} \times 400 \mathrm{~m} \times 400 \mathrm{~m}$ by preliminary calculation, taking into account the size of the flame and its influence range. The appropriate grid size is determined through many calculations to ensure numerical calculation prediction. The result is independent of the number of grids, considering the computational efficiency of numerical simulation. Finally, the total number of grids in the model is determined to be 2660000 .

In simulation, we are concerned about the distribution of temperature and thermal radiation near the fire, monitoring points are set at some positions of adjacent tanks to detect the real-time thermal radiation, and the corresponding temperature field distribution is obtained by analyzing the section of calculation domain. Figure 6 shows the slices of the LNG tank fire simulation calculation and the distribution of monitoring points.

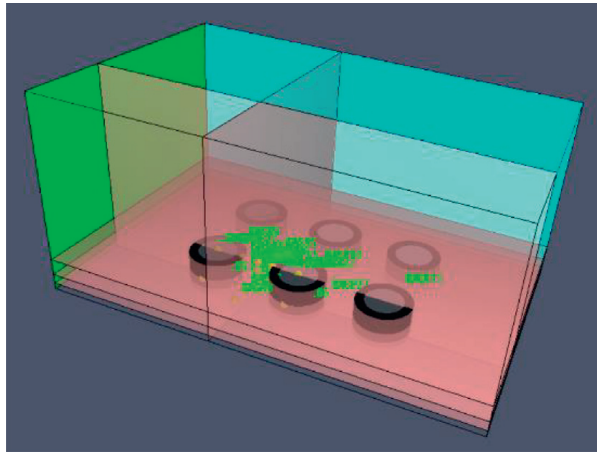

FIGURE 6: Grid division of the LNG storage tank fire simulation and distribution of monitoring points.

\section{Results and Discussion}

4.1. Calculation Results of Release. It is assumed that the leak is located at the height of $6 \mathrm{~m}$ above the ground. According to the relevant data on accidents in the chemical industry 
from 1949 to 1988 in the "Analysis and Prevention of Chemical Equipment Accidents," the general continuous leak has a small aperture of $100 \mathrm{~mm}$ and a large aperture of $200 \mathrm{~mm}$. In this example, 200-mm-large apertures are selected as the leakage apertures. The leakage rate, the maximum radius of the liquid tank, the time it takes for the liquid pool to reach the maximum radius, and the evaporation rate caused by heat conduction are calculated as shown in Table 5 when the evaporation time is $100 \mathrm{~s}$.

\subsection{Results of Wind Field and Dispersion Process}

4.2.1. Analysis of Wind Field in Tank Farm. Figure 7 shows the cloud map of wind speed distribution in the LNG tank farm. The initial ambient wind speed is $5 \mathrm{~m} / \mathrm{s}$. From the horizontal wind speed distributed cloud image, we can see the wind speed distribution at different horizontal positions $35 \mathrm{~m}$ above the ground. From the horizontal wind speed distributed cloud image, it can find that the wind field skips both sides of the storage tank at a relatively high speed because the wind is in the arc tank of the storage tank. The flow around the wall makes the wind speed on both sides of the tank wall reach about $8 \mathrm{~m} / \mathrm{s}$. The vertical wind speed distribution cloud chart shows the wind speed at different heights in the vertical direction. Due to the positive blocking effect of the storage tank, the wind disturbance and swirling flow appear between the two storage tanks, resulting in the obvious weakening of the wind field between the two storage tanks. The wind speed was only $1 \mathrm{~m} / \mathrm{s}$, and it even appeared in some locations. The air retention phenomenon causes the wind speed to be $0 \mathrm{~m} / \mathrm{s}$. Because wind also circulates at the arc-shaped top of the storage tank, the wind speed in a large area above the top of the storage tank is relatively high, reaching about $8 \mathrm{~m} / \mathrm{s}$. There is no obstacle after the most downstream storage tank, so the low wind speed area in the downwind direction of the storage tank is extended.

\subsubsection{Analysis of LNG Evaporation and Dispersion Process.} The hazards of LNG leakage and dispersion are mainly determined by the hazards of its combustion and explosion. The potential hazard of LNG combustion and explosion mainly depends on the dispersion range of LNG vapor cloud leakage within the explosion limit. Once the methane air mixed vapor cloud within the explosion limit meets the ignition source, it is likely to cause fire and explosion accidents, which will harm the surrounding personnel and equipment. The harm scope of vapor cloud reaching explosion limit is analyzed and studied, and scientific suggestions are put forward to reduce the harm of LNG dispersion leakage.

Figures $8(\mathrm{a})-8(\mathrm{f})$ is the distribution map of methane vapor cloud with a volume concentration of $5 \%$ at different times of LNG leakage. The dispersion behavior of methane LEL (Lower Explosion Limited) vapor cloud at the lower explosion limit can be obtained. During the expansion process of methane vapor cloud, due to the disturbing effect of wind, it is easy to accumulate and form vapor cloud in areas with relatively slow wind speed. Due to the barrier
TABLE 5: Leak calculation results.

\begin{tabular}{lcccc}
\hline $\begin{array}{l}\text { Leakage } \\
\text { aperture } \\
(\mathrm{mm})\end{array}$ & $\begin{array}{c}\text { Leakage } \\
\text { rate }(\mathrm{kg} / \mathrm{s})\end{array}$ & $\begin{array}{c}\text { Maximum } \\
\text { radius time } \\
(\mathrm{s})\end{array}$ & $\begin{array}{c}\text { Maximum } \\
\text { liquid pool } \\
\text { radius }(\mathrm{m})\end{array}$ & $\begin{array}{c}\text { Evaporation } \\
\text { rate }(\mathrm{kg} / \mathrm{s})\end{array}$ \\
\hline 200 & 436.6 & 65.3 & 41.8 & 675.2 \\
\hline
\end{tabular}

effect of the storage tanks, vapor cloud accumulation occurred in the space between \#5 and \#6 storage tanks. With the increase of the accumulation volume of the vapor cloud, the position of the vapor cloud slowly increased and moved toward \#6. The top of the storage tank spreads gradually. Due to the high density of $5 \%$ vapor clouds, it is more susceptible to gravity to make the horizontal and vertical dispersion distances shorter than those of low-concentration vapor clouds. As shown in Figure 8(e), when $t=260$, it can be seen that the range of vapor cloud in the top area of \#5 storage tank is small, and most of the vapor cloud is concentrated near the ground and the wall of \#5 storage tank. A large number of vapor cloud is accumulated in the middle area of \#5 and \#6 storage tanks, and with the accumulation of vapor cloud, the vapor cloud is gradually lifted to the top area of \#6 storage tank and slowly diffuses to the top of \# 6 storage tank under the action of wind; \#6 storage tank is near the ground. There is a vapor cloud nearby.

Figure 9 shows the change trend of methane vapor cloud area with $5 \%$ concentration over time. With the extension of the leakage time, the area of the explosive vapor cloud continues to expand. At about $300 \mathrm{~s}$, the dispersion area of vapor cloud in the explosion limit is stable.

To study the distribution of vapor cloud concentration near the ground, Figures 10(a)-10(f) shows the distribution of methane vapor cloud near ground concentration in different time periods. The vapor cloud within the explosion limit is close to the ground, centered on the leakage, and continuously spread in the downwind direction. The concentration of methane gas at the center is darker and more concentrated, and the concentration gradually decreases toward the two sides. In the early stage of the leak, due to the low temperature and high density of the vapor cloud, gravity was the main driving force during the dispersion process. The gas cloud was dominated by lateral distribution, and the vapor cloud was flat and wide. With the mixing of air, the density of vapor cloud gradually decreases, and the atmospheric turbulence gradually replaces the sedimentation of gravity and becomes the main driving force of gas cloud dispersion. As shown in Figure 10(f), when $t=300 \mathrm{~s}$, the dispersion is stable, and it can be seen that the large area near the ground and between the two storage tanks of \#5 and \#6 tanks are within the explosion limit. If this area encounters an open fire, it will cause an explosion accident, and there are often frequent personnel activities and more process equipment near the ground. Therefore, the danger level in this area is high, and the personnel in this area should be given priority to evacuate as soon as possible in case of leakage.

As shown in Figure 11, in the early stage of the leak, the vapor cloud within the explosion limit was mainly concentrated in the range of $0-40 \mathrm{~m}$ from the ground. With the 

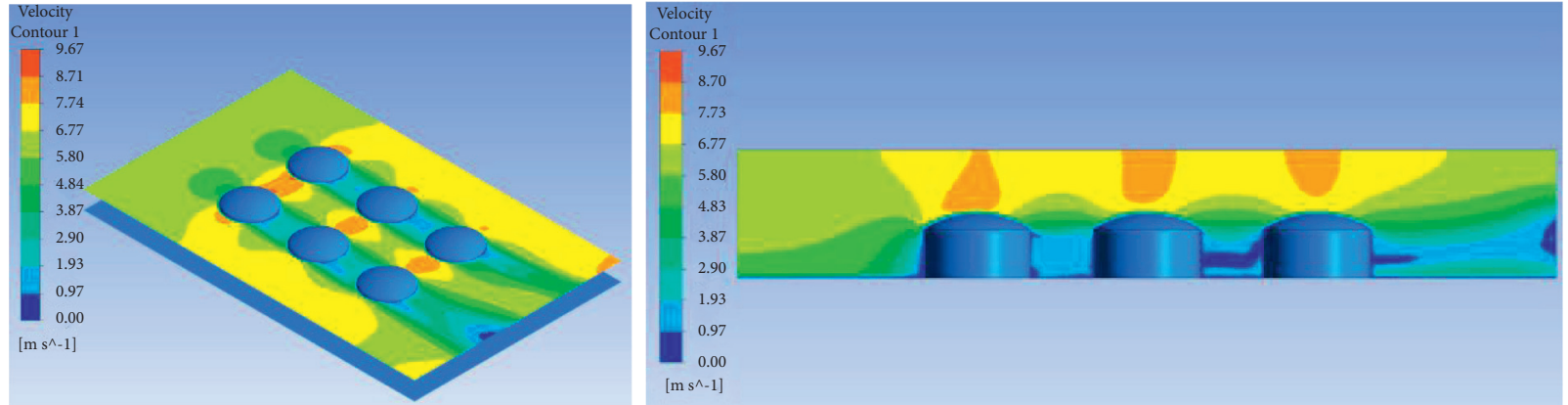

Figure 7: Horizontal and vertical distribution of wind speed in LNG tank farm.

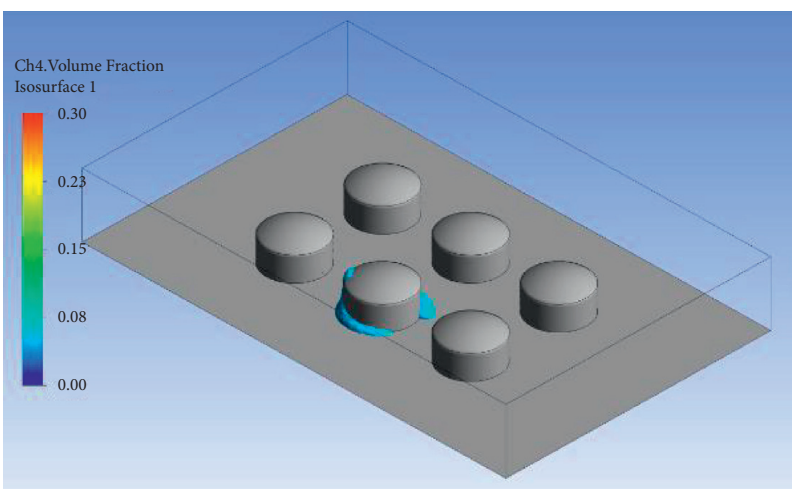

(a)

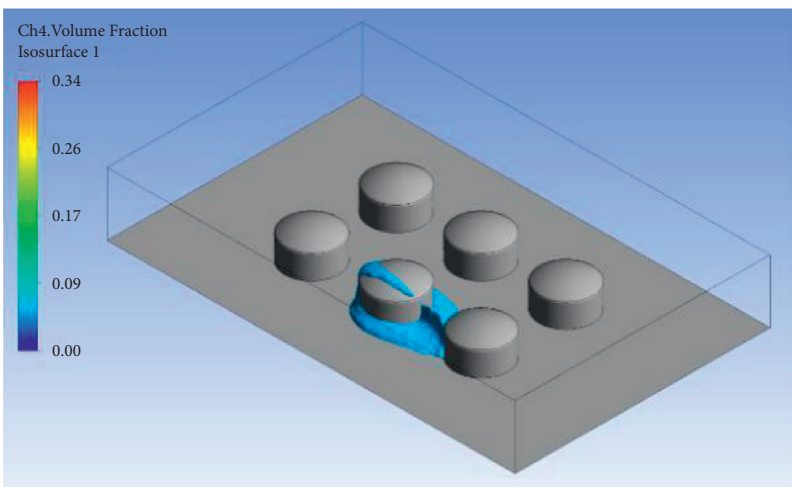

(c)

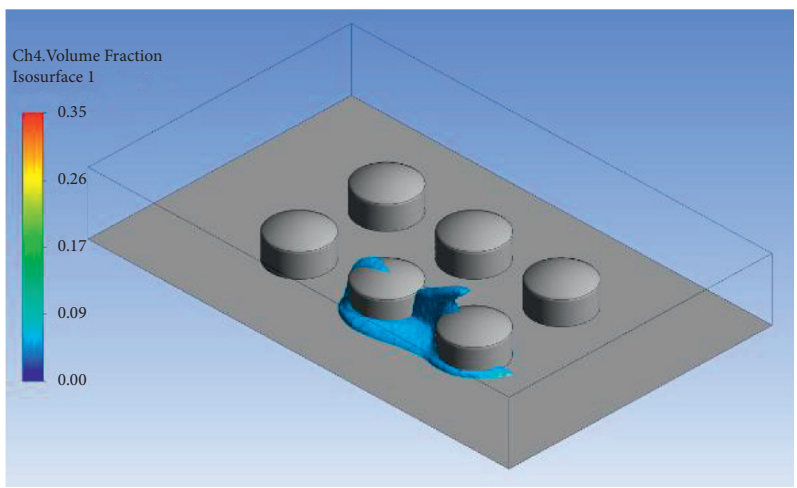

(e)

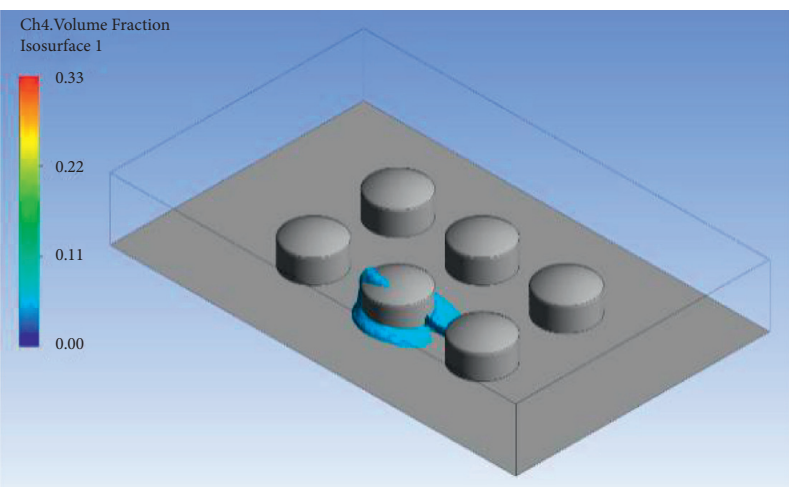

(b)

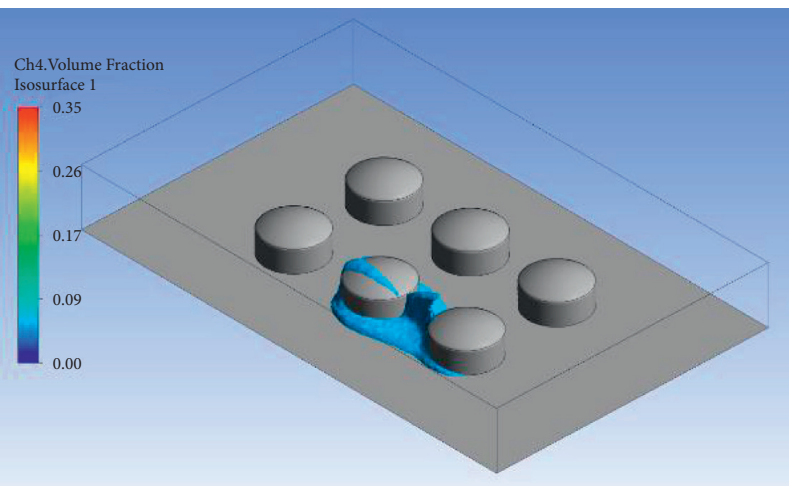

(d)

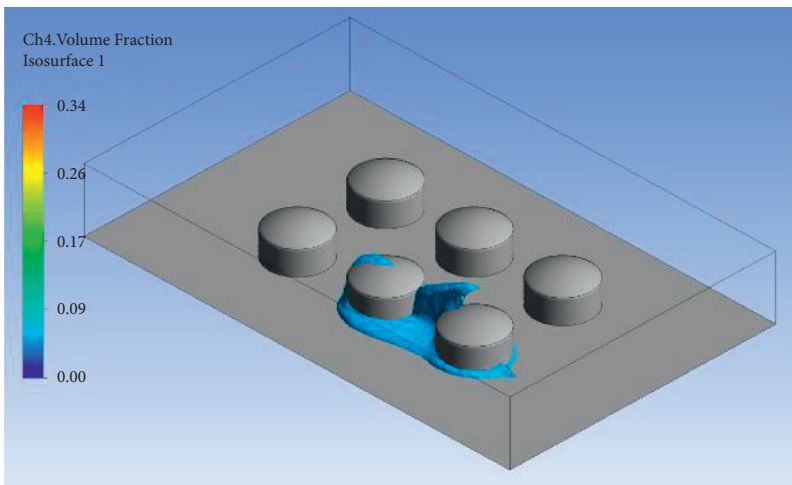

(f)

Figure 8: Surface of LNG vapor cloud with a volume concentration of $5 \%$. (a) $t=50 \mathrm{~s}$. (b) $t=100 \mathrm{~s}$. (c) $t=150 \mathrm{~s}$. (d) $t=200 \mathrm{~s}$. (e) $t=260 \mathrm{~s}$. (f) $t=300 \mathrm{~s}$. 


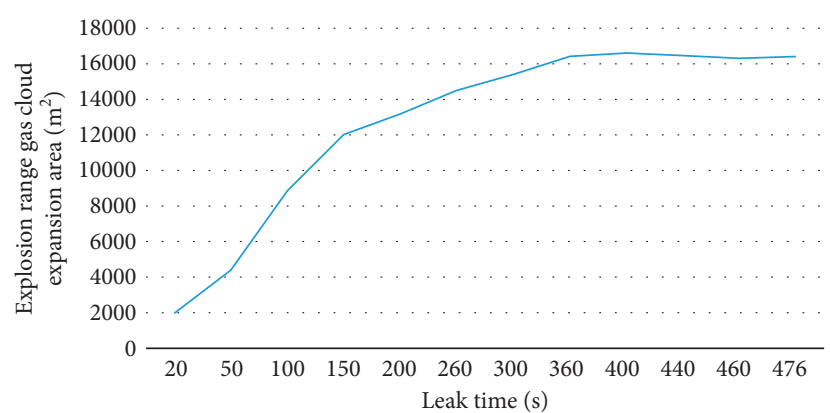

FIGURE 9: Expansion area of LNG storage tank leaking and exploding vapor cloud.

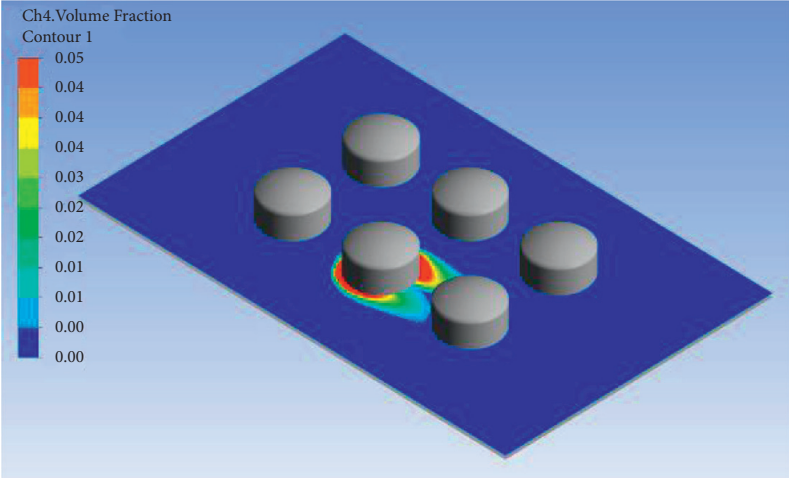

(a)

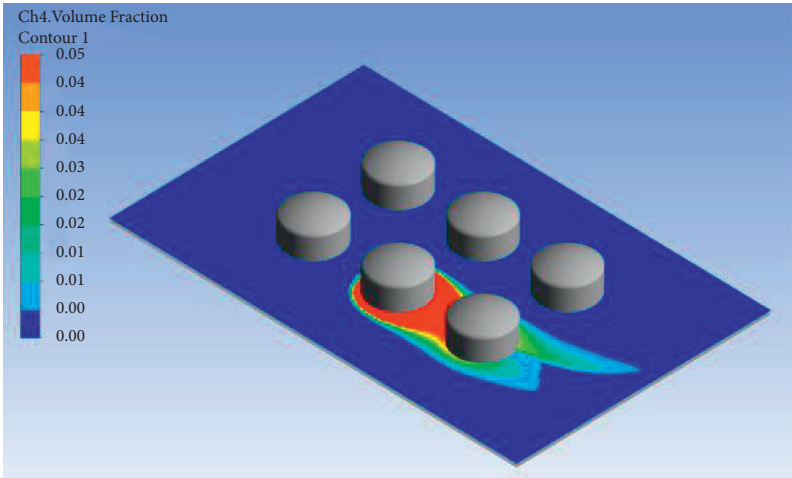

(c)

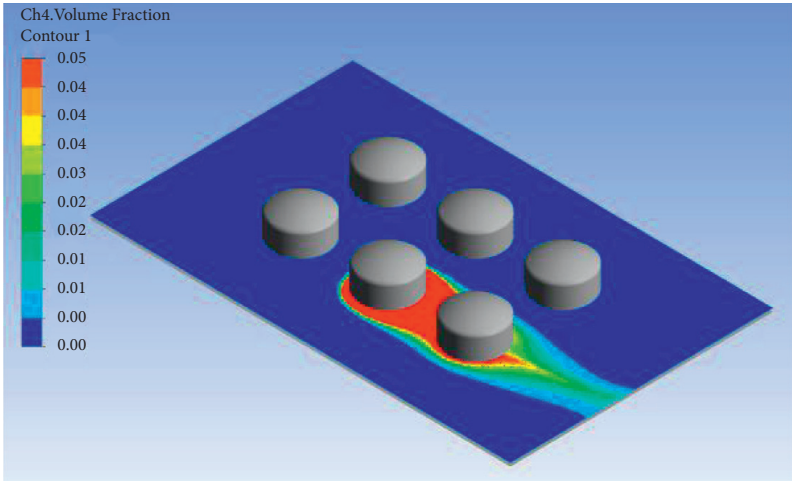

(e)

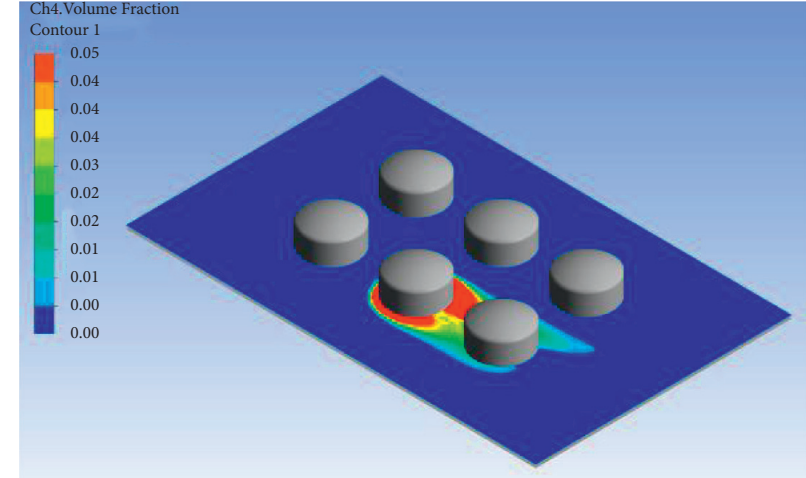

(b)

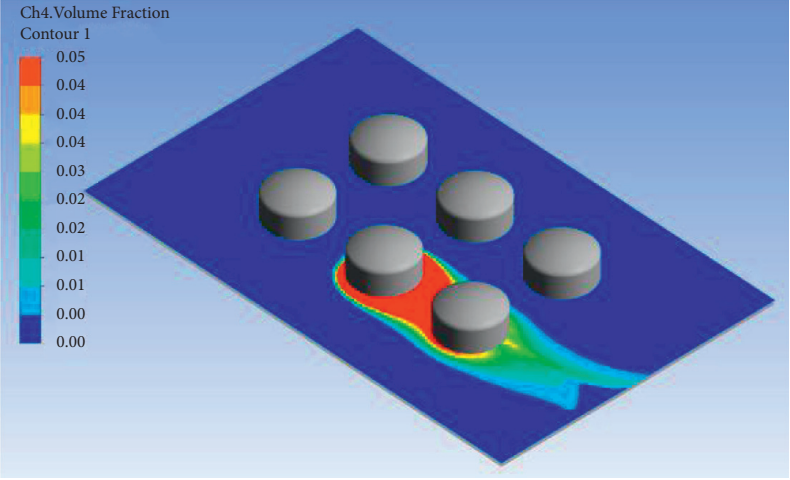

(d)

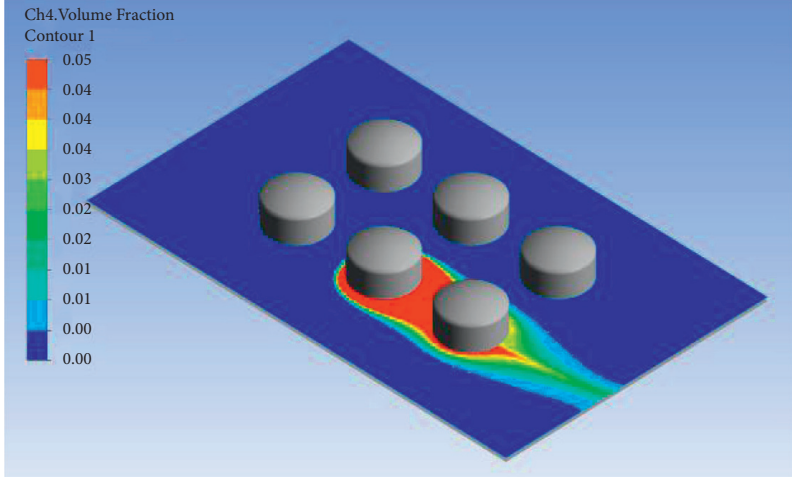

(f)

Figure 10: Methane concentration distribution near the surface of LNG leakage. (a) $t=50 \mathrm{~s}$. (b) $t=100 \mathrm{~s}$. (c) $t=150 \mathrm{~s}$. (d) $t=200 \mathrm{~s}$. (e) $t=260 \mathrm{~s}$. (f) $t=300 \mathrm{~s}$. 


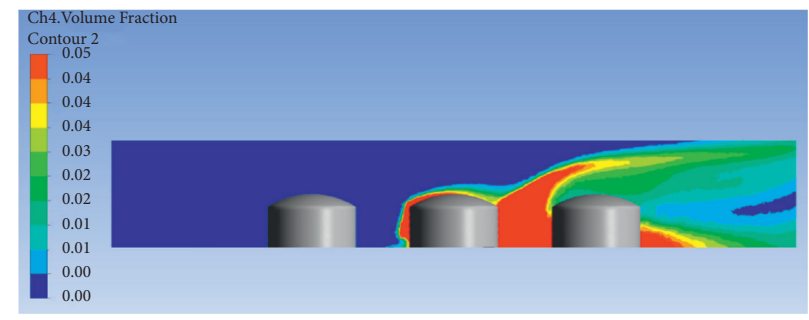

FIGURE 11: Longitudinal distribution of gas cloud with 5\% concentration of LNG storage tank leaking 300 seconds.

disturbance of the air, it began to spread in the downward wind direction. The tank wall surface of tank \#5 upwind and tank \#6 downwind near the ground, and a large area between tanks \#5 and \#6 has been in the explosion limit range. Therefore, this area is a dangerous area that endangers people's lives and the safety of related equipment and facilities if the explosion occurs and will become the secondary hazard unit of the domino effect of the leakage accident.

\subsection{Calculation Results of Pool Fire}

4.3.1. Flame Development Law of Tank Side Leakage Pool Fire. As shown in Figure 12(a), the LNG leaked to the ground to form a stable liquid pool, and as sighted, the liquid pool was burning violently for about 5 seconds. The flame became lenient with its dispersion, and the fire began to spread upward rapidly.

As shown in Figure 12(b), the flame's height has exceeded the storage tank after burning for about $10 \mathrm{sec}-$ onds. The fire is a stage of rapid development at this moment. The blaze below the storage tank height will no longer expand to the surrounding due to the obstruction of the tank wall, and the fire above the highness of the storage tank is blocked by no obstacles around it and is insufficient contact with the air. Under the airflow action, the methane diffuses to the surroundings to make the flame lenient, and the blaze is like a mushroom cloud.

As shown in Figures 12(c) and 12(d), the combustion has been steady in about 20 seconds, forming a stable fire column, and the flame direction is upright. As a result of the combined action of the air generated by the flame, the flame is twisted, showing a clear S shape. There was no significant change in the fire intensity until about 100 seconds.

4.3.2. Temperature Field Analysis of LNG Tank Fire. High temperature is one of the leading evaluation indicators to measure the scope of fire damage. After the fire, the temperature of the flame flow area rises rapidly, which may cause specific damage to the LNG reinforced concrete structure, other equipment, and related operators.

Figure 13 shows the temperature field distribution when the fire is fully developed, and the maximum temperature of the fire-affected area is about $670^{\circ} \mathrm{C}$. According to the influence criteria of flue gas flame temperature on reinforced concrete structure and human body, at this temperature, the stucco layer of the LNG storage tank has all fallen off, causing cracks, the protective layer fell off, and the steel bar leaked out, and the steel lost all its strength. It can be known from the vertical section that the high-temperature area of the fire can reach up to about $150 \mathrm{~m}$ in the vertical direction, and the high-temperature area of the fire can be known from the horizontal section concentrated in the lower half of the area between \#4 and \#5 storage tanks. The influence range of fire temperature near the bottom is mainly in the wall of \# 4 storage tank and \# 5 storage tank and its middle area. People who work on the ground should stay away from this area as much as possible to avoid burns.

4.3.3. Thermal Radiation Analysis of LNG Tank Fire. Thermal radiation is a factor that has a more significant impact on personnel, equipment, and rescue. Analyzing the scope of radiation caused by fire can provide scientific suggestions for avoiding thermal radiation damage. Figure 14 shows the change of heat radiation intensity of \#4 and \#5 tank walls affected by the fire with time. The radiation intensity fluctuates over time because the fire is in dynamic.

(1) The Influence of Heat Radiation on the Wall of \#4 Storage Tank. After the fire broke out, the fire kept expanding, and the thermal radiation flux of the tank wall near the fire source began to rise. About 7 seconds after the fire, the maximum thermal radiation flux of the tank wall is about 90 kilowatts per square meter. After that, the heat radiation flux changed with time at high frequency, reaching the maximum value of 624 kilowatts per square meter in about 41 seconds and then began to fluctuate at high frequency with the general trend decreasing. At about 99 seconds, the flame started to offset, so the heat radiation flux at this time suddenly oscillated and surged to 536.5 kilowatts per square meter. After that, the flame direction changed little, and the change of thermal radiation flux has been flattening out. According to the guidelines for the damage of fire thermal radiation to the human body and equipment, the radiation intensity will have a catastrophic effect on the storage tank. A long-term fire may cause the collapse of the \#4 storage tank, which will increase the fire and cause. It may cause a fire in the surrounding storage tanks, cause a domino effect, and cause a large number of casualties, forming a catastrophic accident.

(2) The Influence of Heat Radiation on the Wall of \#5 Storage Tank. After the fire broke out, the fire continued to expand, and the thermal radiation flux of the tank wall near the fire source began to rise rapidly. The fire occurred for about 7 seconds, and the maximum thermal radiation flux at the tank wall was about 194.5 kilowatts per square meter. Then, 


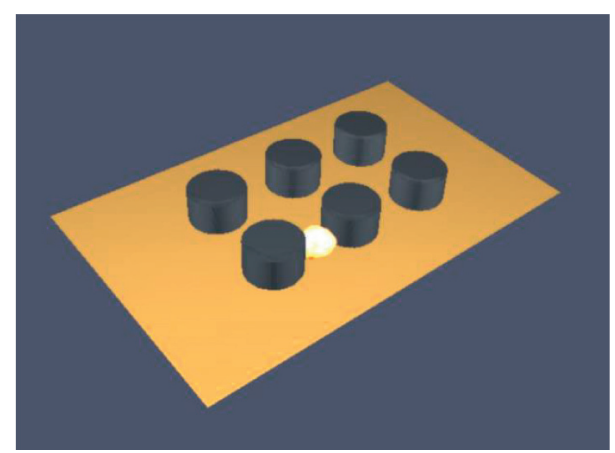

(a)

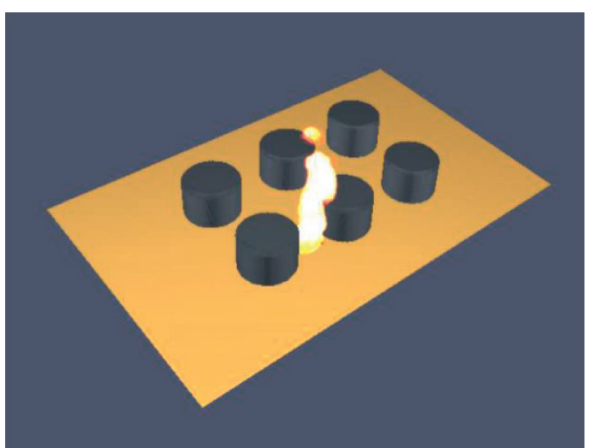

(c)

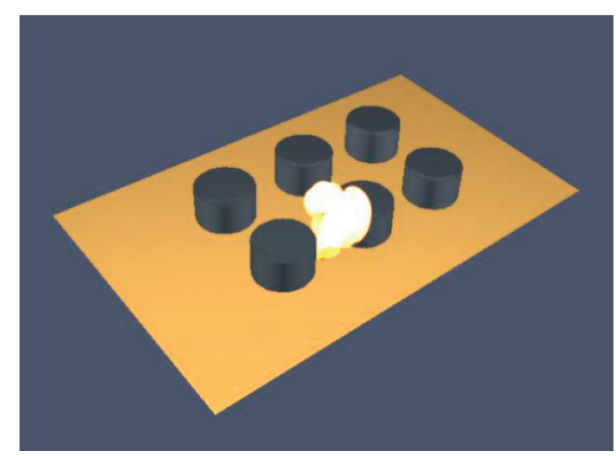

(b)

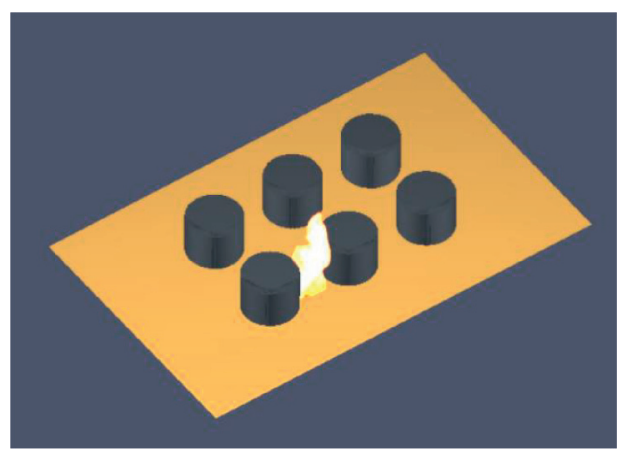

(d)

Figure 12: Fire development diagram. (a) $t=5 \mathrm{~s}$. (b) $t=10 \mathrm{~s}$. (c) $t=20 \mathrm{~s}$. (d) $t=100 \mathrm{~s}$.

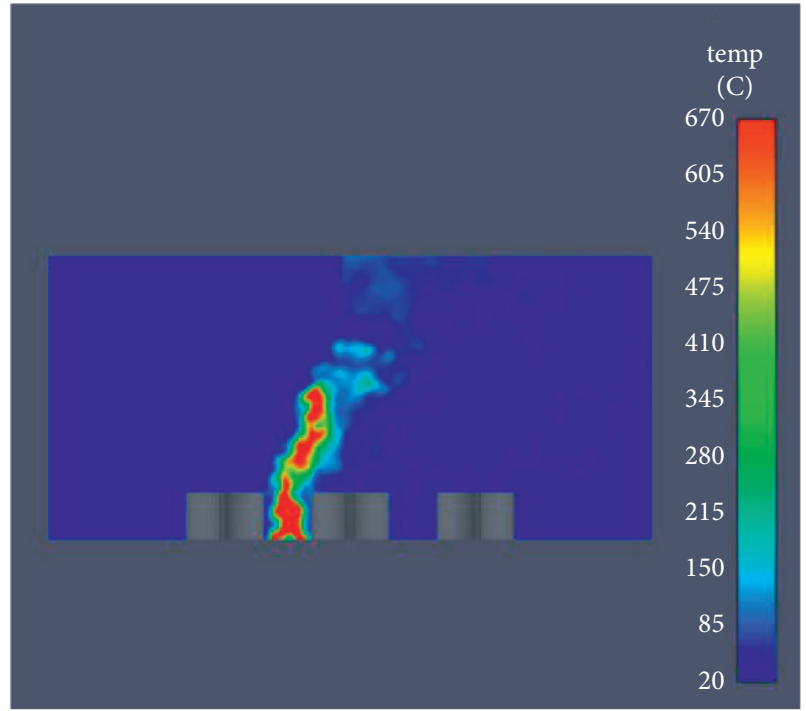

Vertical section

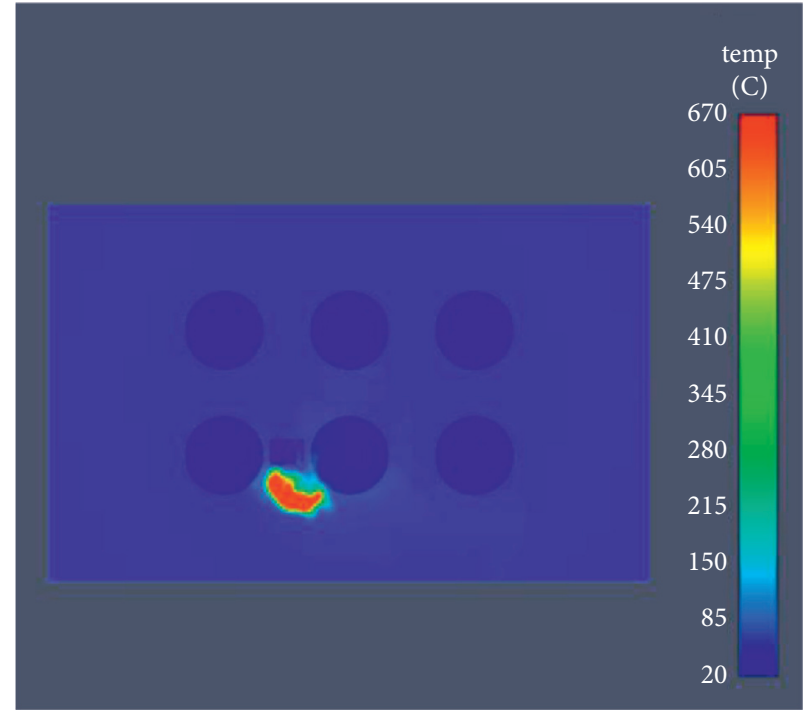

Horizontal section

Figure 13: Cross-sectional temperature field when the fire is fully developed.

there was a small peak at about 16 seconds, and the thermal radiation flux was about 251.4 kilowatts per square meter. Then, the change of heat radiation flux tends to be flat. After that, the heat radiation flux began to rapidly decrease to about kilowatts per square meter. After that, the heat radiation flux began to decrease rapidly to about 65 kilowatts per square meter, and the change of heat radiation flux tended to be flat. According to the damage criterion of heat radiation flux to the human body and equipment, steel materials such as the \#5 storage tank and surrounding pipelines will be seriously damaged under this heat radiation intensity. If the fire lasts for more than 30 minutes, it may cause the steel structure to collapse. People will die under the action of this heat radiation for more than 1 minute. 

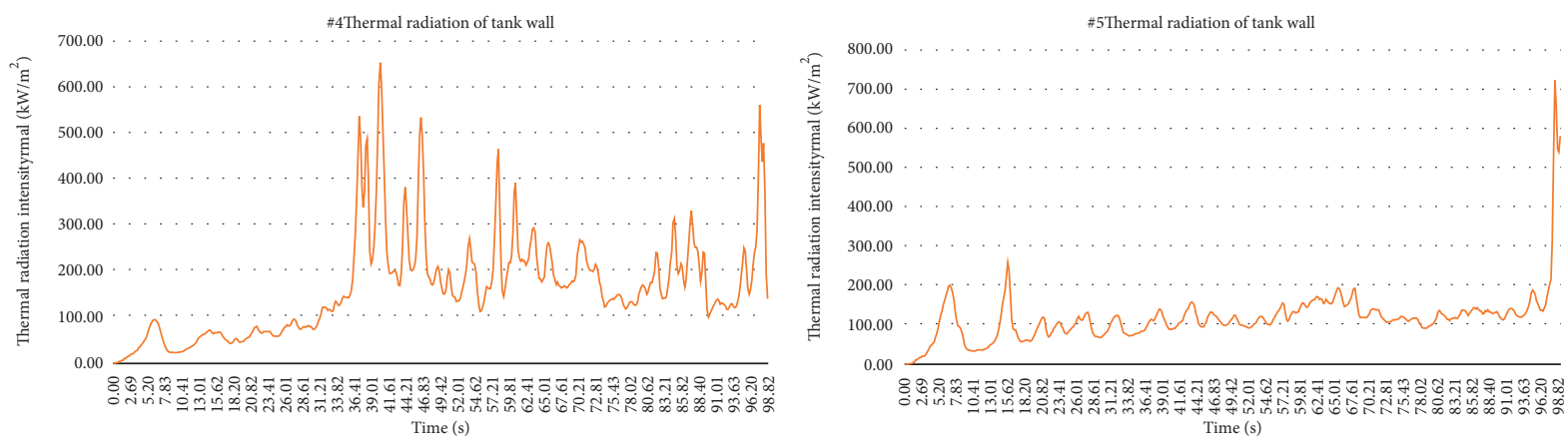

FIGURE 14: Time variation of thermal radiation from tank wall of LNG storage tank. (a) Variation curve of heat radiation of \#4 tank wall. (b) Variation curve of heat radiation of \#5 tank wall.

\section{Conclusion}

This article builds a large-scale LNG storage tank leak chain catastrophe consequence assessment model, reveals the disaster mechanism of the LNG phase change dispersion cascade pool fire caused by the storage tank leakage, analyzes the characteristics of the LNG leakage chain disaster, obtains the impact of LNG leakage on personnel, equipment, and the impact of environmental safety. However, the purpose of this study is to present the cascading disaster due to LNG tank leak. The effect of environmental conditions on dispersion is not included in the scope of this study.

When leakage lasts for about $300 \mathrm{~s}$, the dispersion reaches a stable state. The flammable gas cloud coverage area is maintained at about 16,250 square meters. Fire accidents are prone to occur in the case of ignition sources, and a domino effect is formed. Damage to other storage tanks, related equipment, and operators occurs. The LNG leaked to the ground to form a stable liquid pool and was ignited. The liquid pool burned vigorously in about 5 seconds, and the flame spread to the surrounding area. The flame height was higher than the storage tank in about 10 seconds, and the fire was mushroom shaped. The combustion has been stable in about $20 \mathrm{~s}$, forming a stable pillar of fire; the flame covers the whole tank top area in about 5 seconds. The maximum temperature of the fire-affected area reached about $670^{\circ} \mathrm{C}$. The high-temperature area can reach a maximum of about $150 \mathrm{~m}$ in the vertical direction. The maximum thermal radiation of fire to the \#4 storage tank is 624 kilowatts per square meter and that to the \#5 storage tank is 251.4 kilowatts per square meter. The thermal radiation of \#4 and \#5 storage tank is greater than the maximum injury index. Long time action will cause storage tank collapse and cause a number of casualties.

\section{Abbreviations}

CFD: Computational fluid dynamics

FDS: Fire dynamics

LNG: Liquefied natural gas

LES: Large eddy simulation

LEL: Lower explosion limited

$Q_{L}: \quad$ The leakage mass flow

A: $\quad$ The hole area
$C_{d}: \quad$ The liquid leakage coefficient

$\rho_{1}$ : The liquid density in the storage tank

$h$ : The height of the leakage location from the fluid level in the tank

$P_{t}: \quad$ The pressure in the storage tank

$P_{0}$ : The pressure of the external environment

$r$ : The radius of the liquid pool

$t$ : Time

Q: $\quad$ The mass flow rate of the liquid that leaks to the ground to form The liquid pool

$\rho_{2}: \quad$ The density of the liquid LNG

$k$ : The thermal conductivity of the substance

$B: \quad$ The area of the liquid pool

$T: \quad$ The ambient temperature

$T_{0}$ : The boiling point of the liquid under normal pressure

$H$ : The latent heat of vaporization of the liquid

$\alpha$ : The thermal dispersion coefficient

$\rho: \quad$ The density

$\varphi$ : $\quad$ The general variable

$\Gamma: \quad$ The dispersion coefficient

S: $\quad$ The source term

$G_{k}$ : The turbulent energy term due to the existence of the velocity gradient

$G_{b}: \quad$ The turbulent energy item due to buoyancy

$g_{i}$ : The component of gravity in the direction

$\beta$ : $\quad$ The coefficient of thermal expansion

$p_{\gamma_{i}}: \quad$ The Prandtl number

$\gamma_{i}$ : The mass content of substance $i$

$\overline{J_{i}}: \quad$ The mass dispersion rate of the substance

$T_{\text {mix }}$ : The unit temperature of the mixing zone

$T_{\text {sat }}: \quad$ The saturation temperature

$m_{l \longrightarrow v}$ : The phase change rate of the liquid phase into the gas phase

$m_{v \longrightarrow l}$ : The phase change rate of the gas phase into the liquid phase

$b$ : A factor that controls the intensity of the phase transition

$\alpha_{l}$ : The surface tensions of the liquid phases

$\alpha_{v}$ : The surface tensions of the gas phases

$\rho_{l}$ : $\quad$ The density of liquid phase

$\rho_{v}: \quad$ The density of gas phase

$\rho_{g}: \quad$ The gas density 


$\begin{array}{ll}u: & \text { The velocity vector } \\ p: & \text { Pressure } \\ f: & \text { The external force vector } \\ \tau_{i j}: & \text { The viscosity vector } \\ h_{e}: & \text { The enthalpy value of leakage gas components } \\ q: & \text { The radiant heat flux } \\ \varphi: & \text { The dissipation rate } \\ Y_{i}: & \text { The mass fraction of the } i \text {-th component of the } \\ & \text { leakage gas } \\ D_{i}: & \text { The dispersion coefficient of the } i \text {-th component. }\end{array}$

\section{Data Availability}

No data were used in this study.

\section{Conflicts of Interest}

The authors declare no conflicts of interest.

\section{Acknowledgments}

The authors gratefully acknowledge the financial supports from the National "Thirteenth Five-Year Plan" National Key Research Plan (2016YFC0801200).

\section{References}

[1] R. P. Koopman, J. Baker, R. T. Cederwall et al., LLNL/NWC 1980 LNG Spill Tests. Burro Series Data Report, UCID-19075Vol. 1, Lawrence Livermore National Lab., Livermore, CA, USA, 1982.

[2] W. J. S. Hirst and J. A. Eyre, "Maplin Sands experiments 1980: combustion of large LNG and refrigerated liquid propane spills on the sea," Heavy Gas and Risk Assessment-II, Springer, Dordrecht, Netherlands, pp. 211-224, 1983.

[3] T. C. Brown, R. T. Cederwall, S. T. Chan et al., "Falcon series data report: 1987 LNG vapor barrier verification field trials," UCRL-CR-104316; GRI-89/0138, Lawrence Livermore National Lab, Livermore, CA, USA, 1990.

[4] G. König-Langlo and M. Schatzmann, "Wind tunnel modeling of heavy gas dispersion," Atmospheric Environment Part A. General Topics, vol. 25, no. 7, pp. 1189-1198, 1991.

[5] D. E. Neff and R. N. Meroney, "Behavior of LNG vapor clouds: wind-tunnel tests on the modeling of heavy plume dispersion," PB-83-109868, Colorado State University, Fort Collins, CO, USA, 1982.

[6] R. K. Calay and A. E. Holdo, "Modelling the dispersion of flashing jets using CFD," Journal of Hazardous Materials, vol. 154, no. 1-3, pp. 1198-1209, 2008.

[7] D. Guo, P. Zhao, R. Wang, R. Yao, and J. Hu, "Numerical simulation studies of the effect of atmospheric stratification on the dispersion of LNG vapor released from the top of a storage tank," Journal of Loss Prevention in the Process Industries, vol. 61, pp. 275-286, 2019.

[8] T. Luo, C. Yu, R. Liu, M. Li, J. Zhang, and S. Qu, "Numerical simulation of LNG release and dispersion using a multiphase CFD model," Journal of Loss Prevention in the Process Industries, vol. 56, pp. 316-327, 2018.

[9] A. Saleem, S. Farooq, I. A. Karimi, and R. Banerjee, "A CFD simulation study of boiling mechanism and BOG generation in a full-scale LNG storage tank," Computers \& Chemical Engineering, vol. 115, pp. 112-120, 2018.
[10] D.-z. Zhu, "Example of simulating analysis on LNG leakage and dispersion," Procedia engineering, vol. 71, pp. 220-229, 2014.

[11] R. Qi, D. Ng, B. R. Cormier, and M. S. Mannan, "Numerical simulations of LNG vapor dispersion in brayton fire training field tests with ANSYS CFX," Journal of Hazardous Materials, vol. 183, no. 1-3, pp. 51-61, 2010.

[12] X. Q. Zhuang, Numerical Simulation for LNG Release \& Dispersion from Large Scale Tank, Wuhan University of Technology, Wuhan, China, 2012.

[13] C. Zhang, Numerical Simulation of Vertical Natural Gas Storage Tank Release and Dispersion, Jiangxi University of Technology, Nanchang, China, 2015.

[14] F. Q. Jiang, Simulation Research on the Influence of Dike Dam on LNG Storage Tank Release and Dispersion, Huazhong University of Science \& Technology, Wuhan, China, 2016.

[15] B. Zhang, G. F. Yu, W. Q. Wu, and Y. W. Hu, "Numerical simulation on LNG spilling and dispersion," Journal of Dalian Maritime University, vol. 39, no. 2, pp. 99-102, 2013.

[16] N. Zhou, L. Chen, X. F. Lv et al., "Analysis on influencing factors of LNG continuous release \& dispersion process from large scale tank," Chemical Industry and Engineering Progress, vol. 38, no. 10, pp. 4423-4436, 2019.

[17] Z. J. Yang, L. Hou, and M. Zhu, "Research on leakage and diffusion of a large LNG storage tank and its influencing factors," Natural gas and oil, vol. 38, no. 1, pp. 47-53, 2020.

[18] S. Li, B. D. Chen, Z. T. Zhang, M. J. Du, and Q. J. Li, "Numerical analysis and research about the thermal response of the LNG storage tank in the fire environment," Journal of Petrochemical Universities, vol. 24, no. 1, pp. 78-81, 2011.

[19] B. Sun, K. Guo, and V. K. Pareek, "Computational fluid dynamics simulation of LNG pool fire radiation for hazard analysis," Journal of Loss Prevention in the Process Industries, vol. 29, pp. 92-102, 2014.

[20] F. Xie, W. Song, Z. Chen, and L. Lv, "Study on pool fire model applied to the fire risk assessment of dichloropropane storage tank farm," Acta Scientiarum Naturalium Universiatis Nankaiensis, vol. 45, no. 3, pp. 100-106, 2012.

[21] J. H. Di and F. Q. Chen, "FDS software simulation for fire consequences of LNG storage tank leaks," Oil \& Gas Storage and Transportation, vol. 32, no. 1, pp. 70-77, 2013.

[22] B. Sun, K. Guo, and V. K. Pareek, "Dynamic simulation of hazard analysis of radiations from LNG pool fire," Journal of Loss Prevention in the Process Industries, vol. 35, pp. 200-210, 2015.

[23] Z. D. Yu and J. L. Wu, "Consequence analysis of leakage accident of large LNG storage tank," Journal of Guangdong University of Petrochemical Technology, vol. 26, no. 4, pp. 90-94, 2016.

[24] W. D. Zhang and Y. X. Zhang, "Simulation of leakage accident of large LNG storage tank based on PHAST software," Petrochemical Safety and Environmental Protection Technology, vol. 30, no. 5, pp. 27-31, 2014.

[25] G. H. Chen and S. B. Cheng, "Consequence simulation on LNG leakage accidents and its quantitative risk assessment," Natural Gas Industry, vol. 27, no. 6, pp. 133-135, 2007.

[26] D. H. Zhou, H. Feng, W. Li, Y. Liu, and M. Zhang, "Application of fire and explosion effect analysis method in risk assessment for LNG storage tank," Industrial Safety and Environmental Protection, vol. 41, no. 10, pp. 54-56, 2015.

[27] T. Baalisampang, R. Abbassi, V. Garaniya, F. Khan, and M. Dadashzadeh, "Modelling an integrated impact of fire, explosion and combustion products during transitional 
events caused by an accidental release of LNG," Process Safety and Environmental Protection, vol. 128, pp. 259-272, 2019.

[28] G. Pio, M. Carboni, T. Iannaccone, V. Cozzani, and E. Salzano, "Numerical simulation of small-scale pool fires of LNG," Journal of Loss Prevention in the Process Industries, vol. 61, pp. 82-88, 2019.

[29] D. Lv, W. Tan, L. Liu, G. Zhu, and L. Peng, "Research on maximum explosion overpressure in LNG storage tank areas," Journal of Loss Prevention in the Process Industries, vol. 49, pp. 162-170, 2017.

[30] M. Jujuly, A. Rahman, S. Ahmed, and F. Khan, "LNG pool fire simulation for domino effect analysis," Reliability Engineering \& System Safety, vol. 143, pp. 19-29, 2015.

[31] T. T. Wei, "Quantitative evaluation on the fire and explosion accident of LNG leakage," Industrial Safety and Environmental Protection, vol. 39, no. 8, pp. 56-59, 2013. 